\title{
Correlation of Pulsatility Index with Intracranial Pressure in Traumatic Brain Injury
}

\author{
Travmatik Beyin Hasarında Intrakranial Basınçla Pulsatilite Indeksinin \\ Korelasyonu
}

\author{
Melek GURA ${ }^{1}$, Ilhan ELMACI ${ }^{2}$, Ramazan SARI ${ }^{3}$, Nilufer COSKUN ${ }^{1}$ \\ ${ }^{1}$ Goztepe Training Hospital, Department of Anesthesiology and Reanimation, Istanbul, Turkey \\ ${ }^{2}$ Acibadem University, Faculty of Medicine, Department of Neurosurgery, Istanbul, Turkey \\ ${ }^{3}$ Goztepe Training Hospital, Department of Neurosurgery, Istanbul, Turkey
}

Correspondence address: Melek GURA / E-mail: melekgura@gmail.com

\begin{abstract}
AIM: In traumatic brain injury (TBI) patients, it is desired to monitor the intracranial pressure (ICP) to assess the cerebral haemodynamics and guide the therapy. The study was designed to see if the pulsatility index (PI) measured by transcranial Doppler ultrasonography (TCD) predicts information about ICP values.

MATERIAL and METHODS: In 52 TBI patients with Glasgow Coma Scale (GCS) score < 9, invasive intracranial monitoring and TCD ultrasonography for PI were performed through five days. ICP, cerebral perfusion pressure (CPP), PI values were recorded and calculated. The correlation and regression analysis between ICP, PI and CPP were investigated in the whole group and in patients with a Glasgow Outcome Score (GOS) of 3-5.

RESULTS: The decline in ICP and PI values was significant through five days. The correlation between ICP and PI was strongly significant $(p<$ 0.0001 ) on days 1, 3 and 5 . In patients with a GOS of 3-5, correlation of ICP and PI was also observed. The only significant correlation observed between CPP and PI was on day 5.

CONCLUSION: The strong correlation observed between ICP and PI through the management period of TBI patients can lead us to use TCD ultrasonography-derived $\mathrm{PI}$ as a guide if invasive monitoring is not available.
\end{abstract}

KEYWORDS: Intracranial pressure, Pulsatility index, Transcranial doppler ultrasonography, Traumatic brain injury

öz

AMAÇ: Travmatik beyin hasarında, tedavinin yönetilmesi ve intrakranial hemodinamiklerin değerlendirilmesi için intrakranial basıncın (ICP) monitörize edilmesi eğilimi vardır. Bu çalışma, transkranial Doppler ultrasonografi (TCD) ile ölçülen pulsatilite indeksi (PI) ölçümlerinin ICP değerleri hakkında ön bilgi verip veremediğinin araştırılması için dizayn edilmiştir.

YÖNTEM ve GEREÇ: 5 gün boyunca Glasgow Koma Skoru <9 olan 52 TBI hastasında invaziv intrakranial monitörizasyon ve TCD ultrasonografi ile PI ölçümleri yapılmıştır. ICP, serebral perfüzyon basıncı (CPP) ve PI değerleri kayıt edilmiş ve değerlendirilmiştir. ICP, PI, ve CPP arasındaki korelasyon ve regresyon analizleri tüm grup için araştırılmıştır.

BULGULAR: ICP ve PI değerlerindeki 5 gün boyunca olan azalma anlamlıdır. ICP ve PI arasındaki korelasyon 1, 3 ve 5 . günlerde kuvvetli bir şekilde anlamlı bulunmuştur ( $p<0,0001$ ). Glasgow Outcome Skoru (GOS) 3-5 olan hastalarda da ICP ve PI değerlendirilmiştir. CPP ve PI arasındaki tek önemli korelasyon 5. günde tespit edilmiştir.

SONUÇ: ICP ve PI arasında bulunan güçlü korelasyon, tedavinin yönetilmesi için invaziv monitörizasyon yapmanın mümkün olmadığı hastalarda PI değerlerinin kullanılmasına yönlendirebilir.

ANAHTAR SÖZCÜKLER: İntrakranial basınç, Pulsatilite indeksi, Transkranial doppler ultrasonografi, Travmatik beyin hasarı

\section{INTRODUCTION}

Management of TBI is aimed at detecting the primary damage that occurred at the moment, evacuate the mass lesions and, in addition, prevent and treat secondary ischaemic damages with delayed clinical presentation $(13,28)$. Over the past two decades, it has been concluded that prehospital management and intensive care-based $\mathrm{TBI}$ management protocols result in significant improved outcomes. However, even though there is no sufficient data for whom ICP monitoring should be performed, patients with a GCS $<9$ and an abnormal CT scan are at high risk of elevated ICP $(1,9,21)$. The fact that TCD is a noninvasive and sensitive method to assess the intracranial dynamics in TBI makes it an ideal tool in neurointensive care units (NICU) $(2,17,30)$. The use of TCD as a predictor of ICP was first described by Klingerhofer et al. They have shown that 
changes of the ICP recordings influenced the flow patterns in TCD (12).

Middle cerebral artery (MCA) flow velocities and PI may help to assess the progression of the injury, correlate well with ICP and guide the treatment protocols if invasive ICP measurements are not available at the $\operatorname{NICU}(2,11,12,19,30)$. Several studies have focused on the changes in MCA flow velocity measurements after head injuries and they reinforce the use of TCD together with multimodality monitoring to understand the patterns of perfusion, oxygenation and autoregulation $(8,15,22,26)$. This study was designed to record the cerebral haemodynamic changes and to evaluate ICP indirectly by TCD, to determine whether the increased $P I$ values recorded with $T$ corresponds to ICP values in TBI patients who are under a dynamic treatment protocol.

\section{MATERIAL and METHODS}

After the institutional ethical committee approved and informed consents were waived, $52 \mathrm{TBI}$ patients treated aggressively at the NICU of Istanbul Göztepe Training Hospital were prospectively reviewed. Patients with post-resuscitation GCS $<9$ in the emergency department, unilateral or bilateral motor posturing and computed tomographic (CT) scans defined according to Marshall classification were included (14). Patients who died within five days of admission, who had organ failure or severe infection prior to admission were excluded. Once seen in the emergency department, the neurological and haemodynamic status of the patients was assessed and the patients were intubated and mechanical ventilation was performed consequently. The CT scans of the patients were performed according to the cerebral and haemodynamic status of the patients on the following days. Patients with an intracranial mass lesion on the admission CT were taken to the operating room for the evacuation of the haematoma. The control of elevated ICP was considered according to the guidelines of Brain Trauma Foundation (4). Once admitted to the NICU, the targeted values were a mean arterial pressure of $90 \mathrm{mmHg}$, CPP $60-70 \mathrm{mmHg}, \mathrm{ICP}<20$ $\mathrm{mmHg}$, central venous pressure $5-10 \mathrm{mmHg}, \mathrm{SaO} 2>95 \%$ and $\mathrm{PaCO} 2$ of $30-35 \mathrm{mmHg}$. The head was routinely elevated at 300 up to improve jugular venous return. Anticonvulsants were administered in case of seizures. Euvolemia, normothermia and normoglycemia were targeted. Antibiotic therapy for the intracranial process was performed with vancomycin, according to the guidelines of the Local Committee of Infection. GOS of the patients were evaluated after 3 months.

The elevation of ICP was managed in three steps; moving from one step to another if the ICP values remained constant (31).

Step 1-If ICP > $20 \mathrm{mmHg}$, slight hyperventilation and targeting a PCO2 off $35 \mathrm{mmHg}$.

Step 2- Mannitol $20 \%$ 0.5-1.0 g/ $\mathrm{kg}$ performed with intermittent boluses watching for plasma osmolarity $<320$ $\mathrm{mOsm} / \mathrm{kg}$. High doses of mannitol $(1.4 \mathrm{~g} / \mathrm{kg})$ used when ICP $>30-40 \mathrm{mmHg}$. CPP maintained at a minimum of $60 \mathrm{mmHg}$ with fluid administration, vasopressors like dopamine or norepinephrine in cases of low arterial pressure values.
Step 3- If ICP remained high, barbiturates and early decision for decompressive craniectomy were took into consideration following a CT scan.

Arterial blood pressure was monitored in all patients by radial artery catheter. A parenchymal catheter with a fiberoptic tip transducer into the frontal region or an intraventricular catheter ( Integra MPM-1) was placed. The ICP catheters were inserted for five days and the catheters were changed if a longer period was required. ICP was measured continuously in a software data. CPP was calculated from the difference between mean arterial pressure and ICP. Daily TCD mean flow velocity measurements of MCA were made by bilaterally and continuously. The TCD measurements were conducted transtemporally using a traditional $2 \mathrm{MHz}$ transducer (DWL). The depth and angle of insonation giving the highest mean flow velocity was chosen. Pathological PI values were considered as $\mathrm{PI}>1.0$. The $\mathrm{PI}$ was calculated according to Gosling index, from the difference between end systolic and diastolic MCA velocities divided by the mean MCA velocity. With every sudden increase of ICP, CT scans were repeated. The first, third and fifth days' measurements were taken into consideration for the statistical analysis.

The statistical analysis was performed in SPSS 15.0 for Windows for data processing and analysis. The definitive analysis was used for mean, standard deviation, minimum and maximum variables. Pearson's Correlation Analysis ( $r$ ) was used for correlations, and the paired samples t-test for the differences between days. Simple Linear Regression analysis was used to achieve the effect of ICP upon PI. The statistical significance of the correlation between the investigated quantitative variables was achieved by the $p$ level and the significance level was recorded as $p<0.05$.

\section{RESULTS}

In an 18-month period, a total of $52 \mathrm{TBI}$ patients treated at the NICU were investigated. The demographic and clinical data of the patients are summarized in Tables I and II. Surgery was performed immediately on 14 patients. 20 of 52 patients had to be managed with barbiturate infusion and decompressive craniotomy had to be performed on 16 of these.

The intracranial haemodynamic parameters were followed for five days, and the $1 \mathrm{st}, 3 \mathrm{rd}, 5$ th days were evaluated. In patients with GOS 3-5, the decline in ICP $(27.75 \pm 6.07,21.75 \pm 4.59$, $15.53 \pm 3.39)$ and $\mathrm{PI}(2.03 \pm 0.68,1.52 \pm 0.33,1.05 \pm 0.30)$ values were strongly significant between days $1-3,3-5$, and 1-5 ( $p<$ 0.001).

The overall results of the 52 patients showed a strong correlation $(p<0.0001)$ between ICP and PI on days 1, 3 and 5 with correlation coefficients of $0.567,0.529$ and 0.779 respectively (Figure 1,2,3). When the patients were evaluated regarding GOS, a significant correlation $(p<0.01)$ with correlation coefficients $r=0.583, r=0.530, r=0.469$ on days 1 , 3, 5 for GOS 3-5 was present (Figure 4). 
Table I: Demographic Data of 52 Patient

\begin{tabular}{|c|c|}
\hline \multirow[t]{3}{*}{ Gender } & $n(\%)$ \\
\hline & $42(80,8 \%)$ \\
\hline & $10(19,2 \%)$ \\
\hline \multicolumn{2}{|l|}{ GOS } \\
\hline & $21(40,4 \%)$ \\
\hline & $31(59,6 \%)$ \\
\hline \multicolumn{2}{|c|}{ Marshall Classification } \\
\hline I & $4(7,7 \%)$ \\
\hline II & $15(28,8 \%)$ \\
\hline II & $22(42,3 \%)$ \\
\hline I & $11(21,1 \%)$ \\
\hline & Means \pm SD \\
\hline Age (Years) & $33,53 \pm 19,60$ \\
\hline GCS & $7,30 \pm 3,59$ \\
\hline LOS (Days) & $20,57 \pm 16,09$ \\
\hline
\end{tabular}

GCS: Glasgow Coma Scale, GOS: Glasgow Outcome Score, LOS: Length of Stay.

Table II: Clinical Data of the Patiens

\begin{tabular}{|l|c|}
\hline Traumatic subarachnoid haematoma & 19 \\
\hline Contusional haematoma & 11 \\
Diffuse oedema & 7 \\
\hline Epidural haematoma & 6 \\
Diffuse axonal injury & 5 \\
Subdural haematoma & 4
\end{tabular}

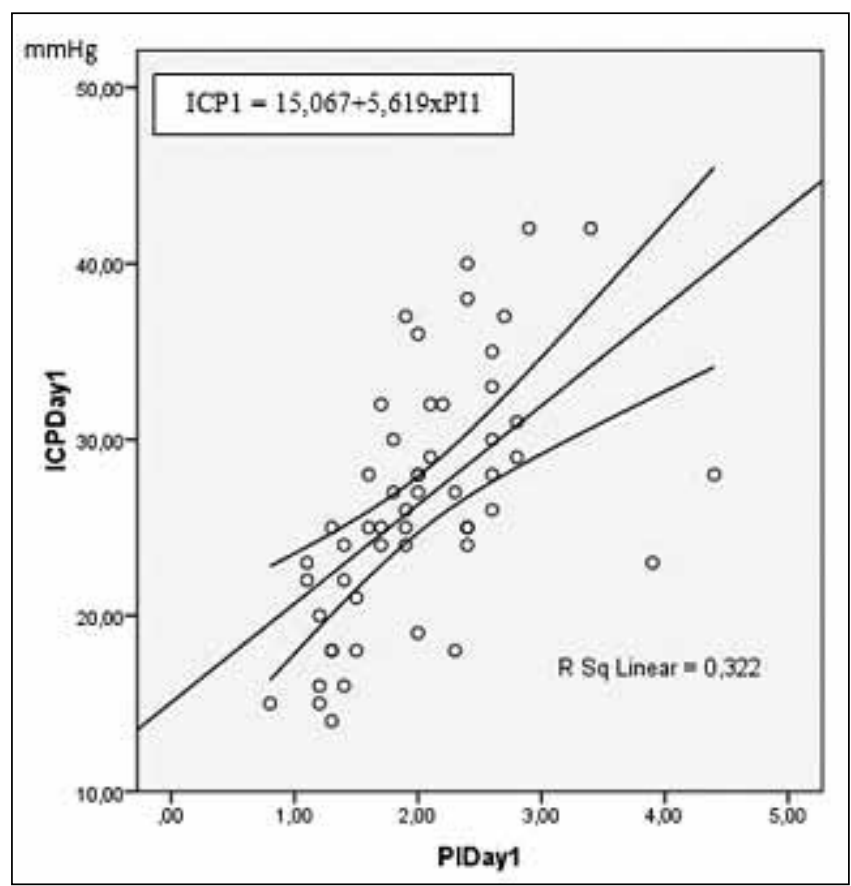

Figure 1: The correlation and linear regression equation of ICP and $\mathrm{PI}$ on the $1^{\text {sd }}$ day in 52 patients.
A negative correlation was found between PI and CPP ( $r=$ $-0.441, \mathrm{p}<0.001$ ) in 52 patients, as CPP increased towards the 5 th day. In patients with GOS 3-5, the correlation of CPP and PI was observed on the 1 st day only (Figure 5,6 ).

The relation between ICP and PI was estimated by the linear regression equation: $\mathrm{ICP}=15.067+5.619 \times \mathrm{PI}$, (the increase of

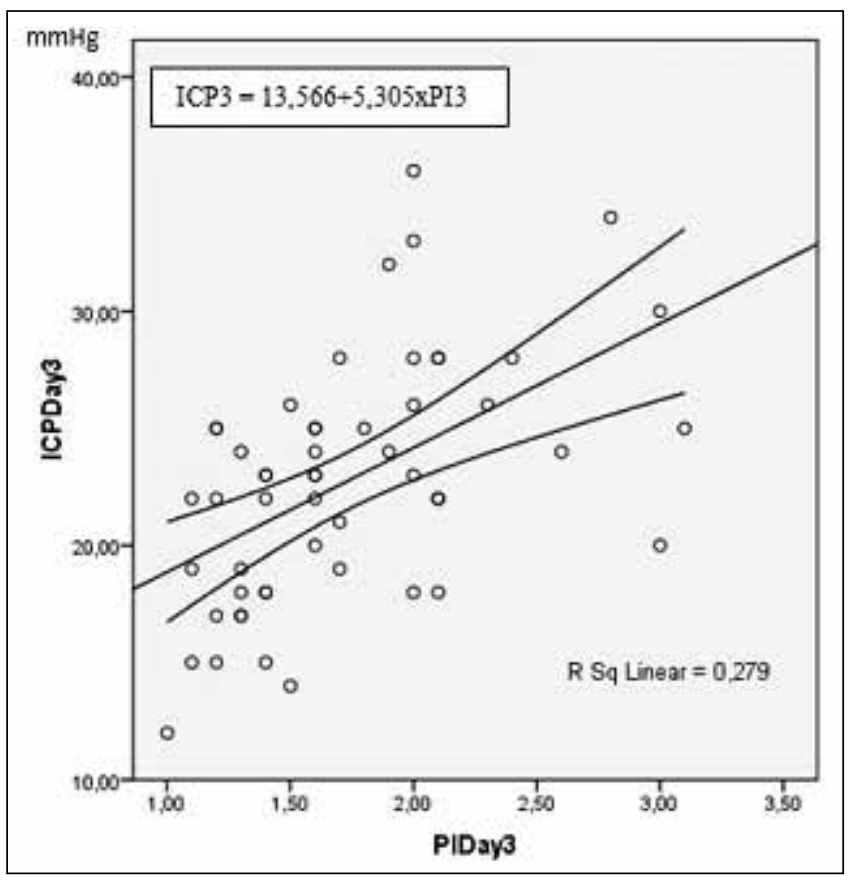

Figure 2: The correlation and linear regression equation of ICP and $\mathrm{PI}$ on the $3^{\text {rd }}$ day in 52 patients.

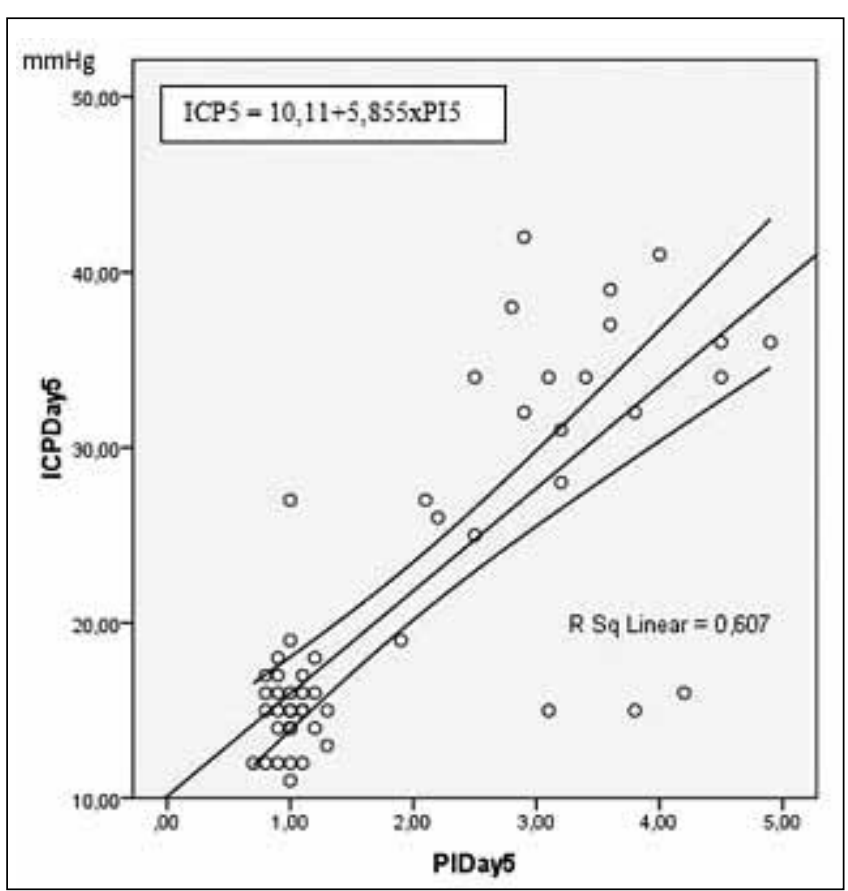

Figure 3: The correlation and linear regression equation of ICP and $\mathrm{PI}$ on the $5^{\text {th }}$ day in 52 patients. 


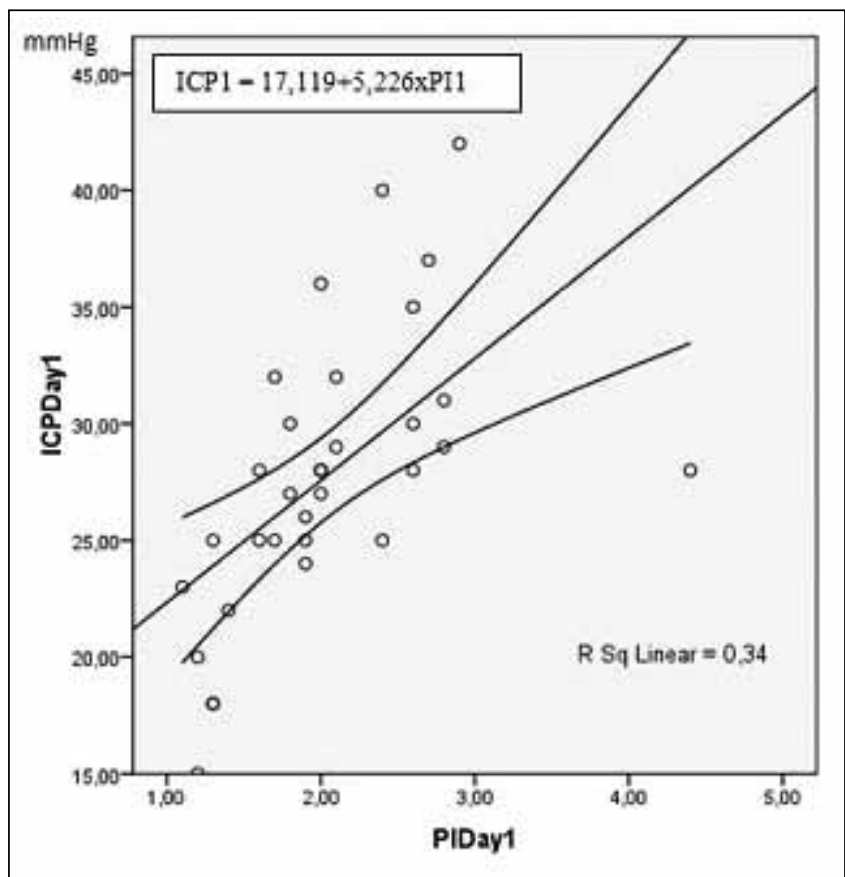

Figure 4: The correlation and linear regression equation of ICP and $\mathrm{PI}$ on the $1^{\text {st }}$ day in patients with GOS 3-5.

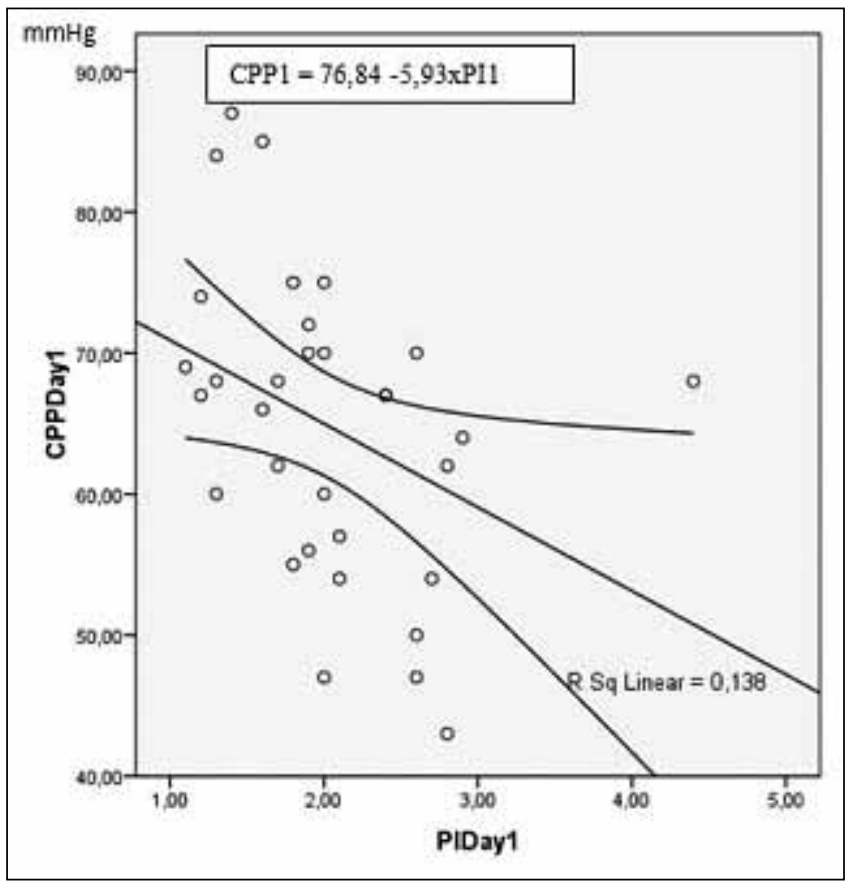

Figure 6: The correlation and linear regression equation of CPP and $\mathrm{PI}$ on the $1^{\text {st }}$ day in patients GOS 3-5.

PI value of one unit is expected to increase ICP value for 5.619 $\mathrm{mmHg}$ on the first day, $\mathrm{r} 2=0.32$ ), ICP $=10.11+5.855 \times \mathrm{PI}$ (for one unit of PI, ICP increased $5.855 \mathrm{~mm} \mathrm{Hg}$ on the fifth day, $\mathrm{r} 2$ $=0.61$ ) (Figures 1,3 ) in patients with GOS 3-5, ICP $=17.119+$ $5.226 \mathrm{x} \mathrm{Pl}$; (one unit of increase in $\mathrm{PI}$ is expected to increase the ICP $5.226 \mathrm{mmHg}$ ) (Figure 4).

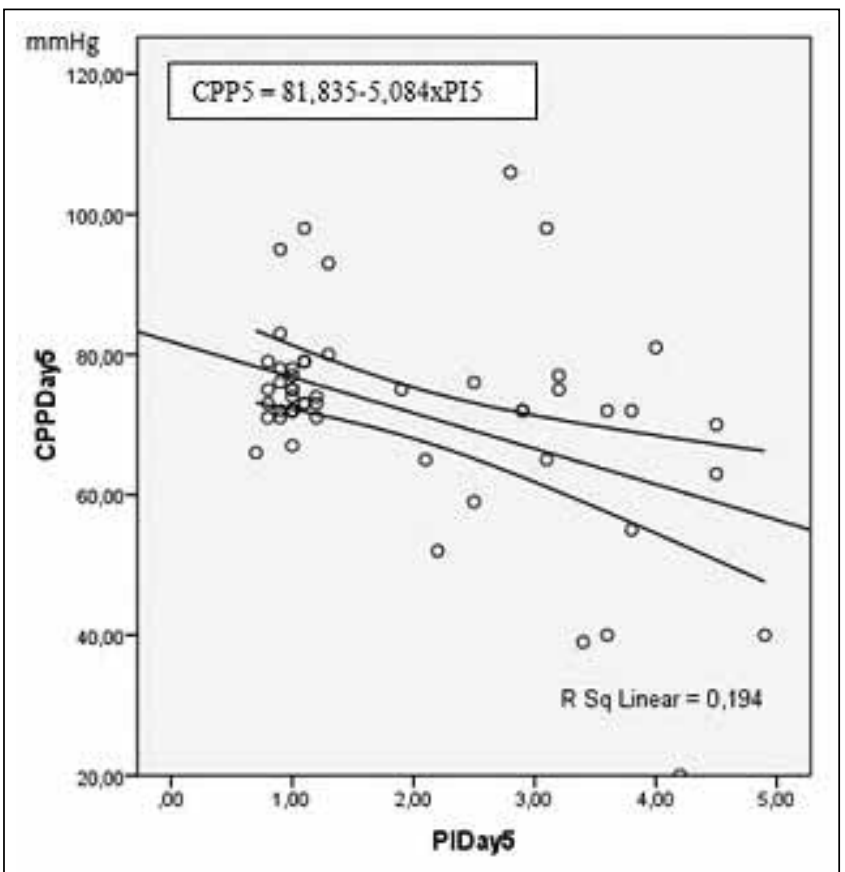

Figure 5: The graphics of correlation and linear regression equation of CPP and PI on day 5 in 52 TBI patients.

\section{DISCUSSION}

Elevated ICP is an important secondary insult in TBI patients. When a direct measurement of ICP is not possible, MCA evaluation with TCD has been proposed as an alternative monitoring technique $(10,16,18,20)$. It has been demonstrated that waveforms obtained with TCD are affected by both increases of ICP or decreases of CPP. When ICP increases due to resistance of cerebral blood flow, diastolic flow velocity decreases and PI increases. Diastolic velocities decrease more than systolic values directly correlated with $\mathrm{PI}$, an indicator of disturbed cerebral perfusion $(15,23)$. Thus, the PI values are indicative of post-traumatic cerebral blood flow and cerebral ischaemia, as well as ICP and CPP. The PI is dimensionless, unitless and independent of angle of insonation $(3,30)$. It is postulated that $\mathrm{PI}$ can be used for noninvasive estimation of ICP in patients with TBI, but it must be known that PI depends on several factors such as arterial pressure pulsatility, heart rate, cerebral perfusion pressure, arterial carbon dioxide concentration, cerebral resistance and compliance of the big vessels $(7,12,30)$.

The present study was conducted to evaluate the patients at high risk of cerebral ischaemia due to elevated ICP and guide the early management strategy in the absence of ICP measurements. During the course of this study, the ICP and TCD measurements were recorded through five days, however the statistical analysis was performed especially for days 1, 3 and 5 , as the ICP values increase and reach a peak value on the third day mostly. The decline of ICP and PI were significant mostly in patients with GOS 3-5, which is noteworthy with the management protocol performed. 
A strong positive correlation was observed between ICP and $\mathrm{PI}$ through the evaluation of three days in all patients (Figure 1,2,3). These data confirm TCD monitoring as a strong indicator of the cerebral dynamics and PI can be evaluated as a predictor of intracranial hypertension.

Several studies on PI and CPP have found that the two variables are correlated closely. A linear correlation has also been observed between ICP and PI in neurosurgical patients $(2,5,10)$.

In the observational study of Bellner et al. 81 patients with various diagnoses including aneurysmal subarachnoid haemorrhage, head injury and encephalitis had an intraventricular catheter for ICP monitoring. Multiple TCD measurements were performed parallel to the ICP recordings. Independent of the intracranial pathology, a significant correlation between PI and ICP and between flow velocity and ICP was found. The correlation was still present in severely elevated $(>120 \mathrm{~cm} / \mathrm{s})$ and subnormal $(<50 \mathrm{~cm} / \mathrm{s})$ values of TCD flow velocity. In the acceptable interval of ICP $0-20 \mathrm{mmHg}$, TCD was defined highly sensitive with a medium specificity. The sensitivity decreased and specificity increased with values over $20 \mathrm{mmHg}$. PI measurements therefore provide a good estimate of ICP in unconscious patients 7 . Homburg et al. have investigated $10 \mathrm{TBI}$ patients and also found a positive correlation of $\mathrm{PI}$ and epidural pressures $(r=0.82)$ and suggested that TCD might be a useful marker of ICP (10).

Splavski et al also, have concluded that measuring the MCA blood velocity after TBI is a worthy tool to estimate ICP, as well as to evaluate early post-traumatic cerebral haemodynamics (24).

A strong significant positive correlation between $\mathrm{Pl}$ and ICP was present on days 1, 3 and 5 in patients with GOS 3-5 (Figure 4). Treatment to lower the ICP values caused the PI to fall towards normal ranges. High PI values demonstrated the risk of secondary insults related to the severity of primary trauma. Early detection of impaired cerebral dynamics allowed immediate therapeutic procedures to be initiated; and an early decision could be made regarding a CT scan, high doses of mannitol, barbiturate infusion or decompressive craniotomy.

Voulgaris et al. have inspected 37 patients with TBI. ICP monitoring and TCD examinations have been carried on subsequently during the first 48 hours. They have found that PI correlated significantly with CPP and ICP. When ICP values were below $20 \mathrm{mmHg}$, the correlation was not significant. When CPP approached the lower autoregulatory limit, PI started to increase rapidly. As CPP decreased from $70 \mathrm{mmHg}$, an inverse correlation between CPP and PI was obtained. PI has had a high predictive value for detecting low CPP and it has been a sensitive indicator for the need to monitor ICP (6).

Chan et al have reported that the decrease of blood velocity corresponds to the increase of PI values and intracranial hypertension correlates with the increased PI values. In this study, they also recorded the correlation between $\mathrm{PI}$ and CPP
$(-0.725)$ and a stronger correlation (-0.942) was found as CPP decreased below $70 \mathrm{mmHg}$ (32).

We observed a less clear correlation between CPP and PI. The correlation was observed on day 5 in the total group and on day 1 in patients with GOS 3-5, with negative correlation coefficients of $-0.372,-0.441$ respectively $(p<0.05)$ (Figure 5,6$)$. These weak findings may be a result of the nonhomogenous group and the small number of traumatic patients.

Moreno et al have performed ICP and TCD in 125 severely injured patients to measure MCA flow velocity and PI within the first 24 hours and have found that Pl increased 0.03 units for each increase of one unit in ICP, and PI increased 0.02 units for each drop of 1 unit in CPP. When they evaluated the variables with GOS, ICP and PI have had an important predictive power and CPP had some predictive value regarding the outcome (16). Splavski et al. have evaluated 24 head trauma patients with ICP and TCD recordings in the NICU. The increased number of hours of intracranial hypertension correlated with low flow velocities of MCA. A significant correlation between ICP and PI has been present. The increase of PI value for one unit increased ICP for 10.834 units. As compared with CPP values, longer duration of decreased CPP was also followed by decreases in flow velocity. They have postulated that the longer the duration of intracranial hypertension, the lower the MCA flow velocity with the TCD measurements limited to the patients with high ICP (23).

The regression analysis of all patients on the 5th day (ICP $=10.11+5.855 \times \mathrm{PI})(\mathrm{r} 2=0.61)$, showed that the ICP value increases 5.855 units for every unit of increase in $\mathrm{PI}$ value. (Figure 3). In patients with GOS 3-5, ICP is expected to increase $4.583 \mathrm{mmHg}$ for one unit of PI (Figure 4).

The study by Steiner et al. on monitoring the injured brain proposed that TCD has a limited precision in ICP monitoring, but it is the simplest way to obtain non-invasive real time estimates of cerebral blood flow for rapid estimation of cerebral blood flow (25). The limitations of TCD are that it measures velocity not flow, measurements are operator dependent, and continuous measurement is not performed easily (27). The authors also state that there are no well designed studies demonstrating a positive effect on outcome from the use of TCD in head injuries. Whilst the PI has been used widely as a predictor of ICP, it is unlikely to replace invasive pressure monitoring (30).

Even though the results of our study seems to be parallel to the ones reported in the literature regarding the correlation of ICP and $\mathrm{Pl}$, the main difference is that, most of them are observational studies and management is not pointed out. In this study, TCD was used as a real time monitor and the three-step therapy protocol was introduced from one step to another according to the measurements obtained. As van Santbrink et al. state, we have concluded that an early insight in post-traumatic cerebral haemodynamics using TCD ultrasonography is important to guide the management protocol and improve outcome (29). According to the results 
of this study, PI may offer an insight for post-traumatic cerebral haemodynamics, and the low cerebral blood flow resulting in low MCA flow velocity and high PI values.

In conclusion;

1. TCD is a simple, noninvasive technique which can be carried out in the early management of TBI even in the absence of ICP monitoring.

2. The potential prognostic value of TCD will guide the therapy for a forceful treatment of intracranial hypertension and help to improve the outcome.

3. Although TCD may not be an accurate substitute for ICP monitoring, it may assist to predetermine the cerebral haemodynamics and outcome.

\section{REFERENCES}

1. Andrews $P$, Citerio $G$, Longhi L, Polderman K, Sahuquillo J, Vajkoczy P: NICEM consensus on neurological monitoring in acute neurological disease. Intensive Care Med 34:1362-1370, 2008

2. Bellner J,Romner B,Reinstrup P, Kristiansson $K-A$, Ryding $E$, Brandt $\mathrm{L}$ : Transcranial doppler sonography pulsatility index (PI) reflects intracranial pressure (ICP). Surg Neurol 62:45-51,2004

3. Bor-Seng-Shu E, Hirsch R, Teixeira M J, Ferreira de Andrade A, Marino R.Cerebral hemodynamic changes gauged by transcranial Doppler ultrasonography in patients with posttraumatic brain swelling treated by surgical decompression. J Neurosurg 104:1, 93-100, 2006

4. Brain Trauma Foundation: The American Association of Neurological Surgeons. The Joint Section on Neurotrauma and critical Care. Recommendations for intracranial pressure monitoring technology. J Neurotrauma May (Supp 1): S45-S54, 2007

5. Chan KH, Dearden NM, Miller JD: The significance of posttraumatic increase in cerebral blood flow velocity: A transcranial Doppler ultrasound study. Neurosurgery 30:697-700,1992

6. Chan KH, Dearden NM, Miller JD: Multimodality monitoring as a guide to treatment of intracranial hypertension after severe brain injury. Neurosurgery 32:547-553, 1993

7. Czonsnyka M: Pulsatility Index. J Neurosurg 94:685-686, 2001

8. Czosnyka M, Smielewski P, Piechnik S, Steiner L, Pickard J: Cerebral autoregulation following head injury. J Neurosurg 95:756-763, 2001

9. Hlatky R, Contant C, Diaz-Marchan P, Valadka A and Robertson C: Significance of a reduced cerebral blood flow during the first 12 hours after traumatic brain injury. Neurocrit Care 1:69-83, 2004

10. Homburg AM, Jakobsen M, Enevoldsen E: Transcranial Doppler recordings in raised intracranial pressure. Acta Neurol Scand 87:488-493, 1993

11. Kincaid MS, Lam AM: Monitoring and managing intracranial pressure Continuum. Crit Care Neuro 12 (1): 93-108, 2006

12. Klingerhöfer J, Conrad B, Benecke R, Sander D: Intracranial flow patterns at increasing intracranial pressure. J Mol Med 65 (12):542-545, 1997

13. Lescot $T$, Abdennour $L$, Boch $A L$, Puybasset $L$ : Treatment of intracranial hypertension. Curr Opin Crit Care 14: 129-134, 2008
14. Marshall LF, Marshall SB, Klauber MR, et al: The diagnosis of head injury requires a classification based on computed axial tomography. J Neurotrauma 9 (1):287-292, 1992

15. Moppett I K. Majahan R P: Transcranial Doppler ultrasonography in anaesthesia and intensive care. Br J Anaest 93(5):710-724, 2004

16. Moreno JA, Mesalles E, Gener J, Tomasa A, Ley A, Roca J, Fernández-Llamazares J: Evaluating the outcome of severe head injury with transcranial Doppler ultrasonography. Neurosurg Focus 8 (1):article 8, 2000

17. Neil MA, Kathleen TM, Caron M:Transcranial Doppler-techniques, application, and instrumentation. Neurosurgery 33:761-763, 1993

18. Rincon F, Stephan M: Neurocritical care: A distinct discipline? Curr Opin Crit Care 13(2):115-121, 2007

19. Saqqur $M$, Zygun D, Demchuk A: Role of transcranial Doppler in neurocritical care. Crit Care Med 35(5): 216-223, 2007

20. Stocchetti N, Longhi E, Zanier R: Intracranial Pressure Monitoring for traumatic brain injury: Available evidence and clinical implications, Minerva Anestesiol 74:197-203, 2008

21. Smith M: Monitoring Intracranial pressure in traumatic brain injury. Anesth Analg 106:240-248, 2008

22. Sorteberg A, Sorteberg W:Transcranial Doppler ultrasonography: part II: Basic principles and applications in neurosurgery. Contemporary Neurosurgery 29(6): 1-7, 2007

23. Splavski B, Radanović B, Muzević D, Has B, Janculjak D, Kristek J, Jukić D: Assessment of intra-cranial pressure after severe traumatic brain injury by transcranial Doppler ultrasonography. Brain Inj 20(12):1265-1270, 2006

24. Splavski B, Radanovic B, Vrankovic B, Has D, Muzevic D, Janculjak $D$, Legcevic J: Transcranial doppler ultrasonography as an early outcome forecaster following severe brain injury. Bri J Neurosurg 20(6): 386-390, 2006

25. Steiner LA, Andrews PJD: Monitoring the injured brain: ICP and CBF. Br J Anaest 97(1): 26-38, 2006

26. Tisdall MM, Smith M: Multimodel monitoring in traumatic brain injury: Current status and future directions. Br J Anaest 99(1): 61-67, 2007

27. Umamaheswara GS, Radhakrishnan M: Benefits and drawbacks of current monitoring modalities in traumatic brain injury. SAARC J Anaesth 1(1): 58-66, 2008

28. van Santbrink H, Schouten JW, Steyerberg EW, Avezaat CJ, Maas Al: Serial Transcranial doppler measurements in traumatic brain injury with special focus on the early posttraumatic period. Acta Neurochir (Wien) 144(11):1141-1149, 2002

29. Werner C, Engelhard K: Pathophysiology of traumatic brain injury. Br J Anaest 99(1): 4-9, 2007

30. White $H$, Venkatesh B: Application of transcranial Doppler in the ICU: A review -Intensive Care Med 32:982-994, 2006

31. Vincent JL, Berre J: Primer on medical management of severe brain injury. Crit Care Med 33(6):1392-1399, 2005

32. Voulgaris S, Partheni M, Kalliora H, Haftouras N, Pessach I, Polyzoidis K: Early cerebral monitoring using the transcranial Doppler pulsatility index in patients with severe brain trauma. Med Sci Monit 11(2):CR49-52, 2005 